\title{
Making sense of energy management practice: reflections on providing low carbon support to three SMEs in the UK
}

\author{
Sam Hampton
}

Received: 10 April 2018 / Accepted: 9 November 2018 / Published online: 17 November 2018

(C) The Author(s) 2018

\begin{abstract}
Energy consumption by small and mediumsized enterprises (SMEs) is collectively significant, and whilst opportunities for substantial, cost-effective efficiency savings exist, take up is low. Whereas research tackling this challenge typically focuses on barriers and drivers to action, this paper offers an alternative perspective, investigating energy management as a practice. Drawing on practice theory and the concept of organisational sensemaking, narrative accounts provide in-depth insights into energy management practice within three SMEs. Auto-ethnographic reflections from 5 years of providing energy and environmental advice are supplemented by findings from carbon footprint assessments and interviews. Findings show that despite energy management being perceived as a peripheral business activity, it is intertwined with organisational identity and knowledge production in each of the three SMEs. Business advisors are instrumental in steering SME energy management practices and have a responsibility to reflect on how they influence processes of knowledge production and meaning-making in organisations. Implications for policy-makers, advisors and the research community are discussed.
\end{abstract}

Keywords SMEs $\cdot$ Energy management $\cdot$ Practice theory $\cdot$ Sensemaking

S. Hampton $(\bowtie)$

Environmental Change Institute, Oxford University Centre for the Environment, Oxford University, South Parks Road, Oxford OX1 3QY, UK

e-mail: samuel.hampton@ouce.ox.ac.uk

\section{Introduction}

Small and medium-sized enterprises (SMEs) consume more than $13 \%$ of global energy (IEA 2015), and significant opportunities for savings and associated emissions exist (DECC 2014). However, energy and environmental literacy is low amongst SMEs (Coles et al. 2016), and many fail to take up cost-effective opportunities for efficiency savings (Revell and Blackburn 2007). A significant literature has developed which addresses the barriers and drivers for energy efficiency investments in different sectors and geographies (Cooremans 2012; DECC 2014; Trianni and Cagno 2011). Comparatively, less attention has been paid to the practice of energy management, and this paper reports on a study which set out to investigate energy management practice in SMEs in close detail. Given that for many smaller organisations, energy management tends to be more informal and peripheral than in larger organisations (Sa et al. 2015); it uses a liberal definition of energy management, incorporating mundane activities such as tweaking thermostats, setting timers, paying bills, switching off appliances and making clothing choices. Beginning with the notion that energy facilitates almost all business activity, it investigates how its management interweaves with other organising processes.

Data is drawn from the authors' professional experience of providing support to SMEs from 2013 to 2018. During this period, I provided face-to-face support to 52 businesses, with the aim of reducing their energy usage and environmental impact. When planning this research, 
I had expected to report insights into (1) how energy is used and managed by SMEs and (2) how they had been able to heed my advice and reduce its usage. Against the first objective, in-depth insights into energy management are presented for three SMEs: a business services provider, a charity and a manufacturer/online retailer. These reveal how energy management practice is woven into organisational narratives and sensemaking processes and the materialities involved in how these play out. The second objective was more problematic. It became clear over the course of the relationships developed with SMEs that the ways they responded to external advice were unpredictable, unexpected and often resulted in little or no reduction in environmental impact. Analysing research findings revealed as much about the practice of providing low carbon advice and processes of organisational meaning-making, as SME energy management. The study therefore pivoted to focus on each practice in equal measure.

Reflecting this meandering research journey, this paper uses narrative techniques to tell stories not only about the three SMEs as they received information and advice relating to their own energy practices, but also as a way of reflecting on the role of low carbon advisors, who both influence, and are influenced by, the SMEs they support. With an interest in both energy management as a practice, and in the processes of organisational knowledge production, the analysis of findings is supported by two conceptual frameworks. Firstly, the concept of sensemaking offers insights into the ways that meanings and norms are products in organisations (Weick 1995; Weick et al. 2005). Secondly, concepts from practice theory are used to draw attention to the socio-material nature of knowledge and practice. Both encourage critical reflexivity when conducting empirical research and helped to highlight the wisdom of expanding the research focus (Schmidt 2016).

The next section locates this study in the context of SME energy and environmental literature and explains how sensemaking and practice theory offer valuable, complementary insights into organisational activity. The methods section explains the processes of sampling and data collection and reflects on the unconventional application of practice theory. Findings from each SME are then presented in the form of three narratives. The penultimate section discusses the practices of SME energy management and advice-giving, reflecting on how the theoretical framework helped to uncover surprising their characteristics. The conclusion focuses on implications for policymakers, advisors and the research community.

\section{Literature review}

Energy consumption, efficiency and environmental impact in SMEs

Research on SME energy consumption and environmental performance has come from a number of disciplines and a range of epistemological traditions, with most studies addressing the problem of under-adoption of energy efficiency opportunities. In their thorough review of energy, behaviour-change and organisational literature, Andrews and Johnson (2016) point to a considerable body of work identifying and evaluating barriers and drivers for the uptake of energy efficiency measures, the majority of which identifies financial constraints as the principle barrier, and the prospect of comparative advantage as the main driver (Fleitera et al. 2012; Trianni and Cagno 2012; Williamson et al. 2006). This literature has been influential in the design of policy instruments for SMEs. Across the EU, incentives such as grants, loans and the provision of expert advice are available to help businesses overcome financial barriers, and to help demonstrate the case for making efficiency investments (Hampton 2018a). Typically, publicly funded advisors focus on technological investments such as low energy lighting, low-carbon heating systems, more efficient machinery or smart technologies (BEIS 2017a; DECC 2016; Warren 2017).

Despite its pervasiveness, the barriers and drivers approach has been subject to criticism. Hampton and Fawcett (2017) raise methodological concerns, pointing to the reliance on surveys and interviews with business owners and managers, who may be more likely to identify financial reasons for inaction, rather than lack of managerial knowledge or other internal factors. Challenges have also been made to the model of decisionmaking underpinning the barriers and drivers literature, which largely assumes that SMEs will act according to rational economic principles when barriers are removed, for instance, by supportive policy (Banks et al. 2012; Revell 2007; Revell and Blackburn 2007). These assumptions have also been contested by empirical research produced for a UK government report, which found that up to $37 \%$ of energy efficiency measures required no capital investment, and yet take-up remained low (DECC 2014).

Drawing on some of the literature cited above, Lutzenhizer (2014) argues that the problematisation of organisational energy consumption and environmental 
performance has been dominated by the physicaltechnical-economic (PTE) model. A 'problem frame' has been created which deals with the problem of energy wastage by addressing the physical characteristics of buildings, the efficiency of appliances and the costeffectiveness of technological measures. This framing marginalises contributions from a wider spectrum of social sciences which ask more fundamental questions about the role of energy in the context of organisational behaviour and social practices (Powells et al. 2015; Janda et al. 2015). Setting out the scope of an expanded research agenda, Lutzenhiser (2014) calls for more indepth, qualitative research, including studies drawing on organisational theory and social practices. This paper responds to this call by applying the principles of organisational sensemaking and practice in its analysis.

\section{Sensemaking}

The concept of sensemaking has been widely used within organisational theory and empirical research, since introduced by Weick $(1979,1995)$. Weick's model conceives of organisations as the outcome of organising processes, as they respond to, and make sense of, collective experiences. Sensemaking research attends to how meanings, identities and knowledge are constructed through processes such as retrospection, performative enactments or the telling of stories (Weick 1995; Weick et al. 2005). The question 'how can I know what I think until I see what I say?' exemplifies the model of performative meaning-making at the heart of sensemaking, and helps to explain why many empirical studies of organisations have used ethnographic methods and narrative accounts.

Currie and Brown (2003), for instance, shadowed hospital middle managers in the UK, attending meetings and conducting interviews to show how the 'confluence' of particular narratives around the notion of patient care served to construct meanings of healthcare practice. Georg and Fussel (2000) conducted another study in a hospital setting, using ethnographic methods to observe how 'organisational greening' was attempted by a dedicated project team. Attending to the emotional dimensions of their participants' experiences, they show how staff experienced anger, frustration and even shame as they came to discover the scale of environmental impact arising from their organisation. The authors describe the awkwardness experienced by practitioners, as they attempted to reconcile this knowledge with their existing internal narratives relating to their professional practice. Narratives are central to each of these accounts, not only as primary data in the form of stories told by participants, but as a means for describing organisational meaning-making and change.

A microscopic examination of sensemaking processes is provided by Abolafia (2010), who deconstructs policy-making narratives in the US Federal Reserve. Through close analysis of meeting transcripts, he shows that sensemaking is a recursive process by which individuals navigate established protocols for decision-making, whilst applying their own 'logic of appropriateness' to challenges encountered in their own roles. This study shows that the principle of 'plausability' trumps accuracy, as facts and events are selectively retained in collective narratives which fit with established norms and meanings. Abolafia's carefully constructed account demonstrates how an attention to sensemaking can uncover how organisational identities are produced and reproduced.

The tradition of sensemaking primarily considers organisations as discursive constructions, relying on relatively conventional ideas about the nature of knowledge (Nicolini 2012). There are exceptions within this school of organisational studies however, including Cunliffe and Coupland's (2012) study of a sports team on tour, in which they uncover how embodied forms of experience and interaction help to deem social activity as sensible, plausible and acceptable. Despite efforts made by authors such as Harquail and King (2010) to develop a research agenda for the study of embodied cognition in organisations, this attention to materialities is relatively undeveloped within sensemaking literature. For Nicolini (2012), this is where practice theory can add significantly to the study of organisations. Sharing similar recursive ontological foundations, epistemological frameworks and an empirical concern with observable activity (Lizardo 2004; Brown et al. 2015), a practice perspective affords greater ontological status to material objects and bodies and has a longer tradition of attending to the these (Bourdieu 1977; Shove 2003; Wilhite 2008).

Practice theory

Practice theory has been extensively applied in organisational studies since the 1990s (Corradi et al. 2010). Feldman and Orlikowski (2011) argue that by moving away from the structure-agency dichotomy, 
practice theory offers an alternative ontological account of the organisation, as emerging from the doings and sayings that occur within and beyond it. Reflecting on practice theory as an alternative paradigm within organisational studies, they point to examples of research which has reconceptualised strategising as a relational and enacted practice (Whittington 2006; Johnson et al. 2007), and knowledge as an ongoing social accomplishment with cognitive and embodied dimensions (Orlikowski 2002).

Schatzki's contribution to Organisational Studies has been influential in emphasising their continually emergent nature. He suggests that organisations are the result of a combination of everyday doings and sayings, and the material arrangements which shape, and are shaped by these (2006). From this viewpoint, an organisation cannot be defined either by the various social practices that take place within its purview, nor the rules, structures and environment in which these are embedded, but is ontologically defined where these two domains meet (Schatzki 2005). Schatzki argues that as the recursive relationship between material arrangements and practices comes endures over time, organisational knowledge becomes embedded and memory is produced (Schatzki 2006).

Also concerned with organisational knowledge and learning, Gherardi $(2006,2009)$ points to organisational studies literature prior to the 'practice turn' which discussed the practice of 'knowledge management' in organisations, considering it as a valuable resource. In parallel with the conceptual shift from 'organisation' to 'organising' (Clegg and Hardy 1996), influences from practice theory helped to move attention from 'knowledge' to 'knowing'. Gherardi emphasises the 'renewed conception of knowledge' offered by the concept of practice, foregrounding the role of materiality and distributed agency, and reconceptualising it as continually emergent, dynamic and collaborative (Lave and Wenger 1991). Developing Schatzki's notion of 'arrangements', Gherardi describes organisations as providing the 'texture of interrelated practices', from which an 'action-net' is formed.

A brief summary of this literature highlights the plethora of terms and concepts used by researchers of organisations and practice theory, which reflects the diversity of practice theory itself (Nicolini 2012; Spaargaren et al. 2016). Nonetheless, there are significant similarities between each of the accounts cited here and in his comprehensive treatise on practice theory and organisations, Nicolini (2012) helpfully describes five distinctive characteristics shared amongst them all (Table 1).

Practice theory has become influential in recent social scientific energy research, being used to highlight how energy use and environmental impacts occur as part of mundane social activity (Shove and Walker 2014). However, the majority of empirical studies using practice theory have focused on the domestic setting, and few studies have applied the principles of practice theory as set out by Nicolini to research on organisational energy use and management (Lutzenhiser 2014; Powells et al. 2015). As with every rule, there are notable exceptions, and these include Powells et al.'s (2015) exploration of the potential for flexibility amongst SME practices, and Hargreaves' (2011) ethnographic study of 'Environment Champions' working within an SME to bring about change in practice. Both demonstrate that practice theory can offer valuable in-

Table 1 Nicolini's characteristics of practice theory $(2013$, p. 6)

Distinctive characteristics of practice theory
Application to investigating energy management practice in SMEs

Questions apparently durable features of our world. Highlights processes of organising which produce apparent stability of social practice.

Forces us to rethink the role of The PTEM foregrounds agents and individuals; e.g. managers, the managed

Foregrounds the body and objects in social affairs.

Sheds new light on the nature of knowledge and discourse.

Reaffirms the centrality of interests and power in everyday practice. apparently stable and routinised energy practices. technical expertise and its focus on investment opportunities engages with senior staff. An attention to mundane energy management practice considers a wider range of actors and their associated practices.

Attends to the elements of energy management practice, including the materials and embodied knowledge involved in its performance.

Paying attention to how various forms of knowledge (embodied, cognitive, shared) is produced and sustained in organisations, and the influence of external advice.

Observing how certain activities or forms of knowledge are produced at the expense of others, asking 'whose interests are served'?
Assists in delving beneath 
sights into energy related practices in small organisations. However, no study has focused specifically on the practice of energy management in SMEs. Table 1 summarises how practice theory is applied to this empirical context in this paper, in accordance with Nicolini's defining characteristics.

In addition to the guiding principles set out by Nicolini, the 'three-element' model is used to support this empirical study (Shove et al. 2012; Shove and Pantzar 2005). This framework breaks down practices into constituent elements, using the categories meanings, materials and competences to highlight their diverse socio-material construction (Fig. 1). The elegant simplicity of the model has attracted a number of energy researchers to use and develop it to support empirical data analysis (Higginson et al. 2015; Spotswood et al. 2015; Kuijer 2014). Following earlier work by Hampton (2018a), it is used in this study as an interview aid, helping to spark ideas and uncover unexpected insights from respondents as they are provided with a framework to help make sense of their practice. This generates insights into the materials, meanings and competences involved in energy management which would have remained unseen investigated using the conventional PTE model.

\section{Methods}

Background and sampling

Empirical data for this paper are drawn from the author's experience of providing business support to SMEs from 2013 to 2018. As an environmental consultant, I support

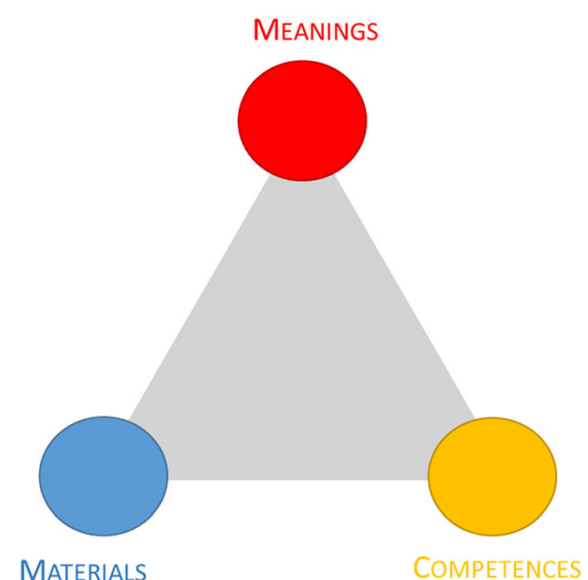

Fig. 1 Three element model of practice theory (Shove et al. 2012) organisations to review their energy consumption and environmental impact and provide advice and recommendations for energy, emissions and cost savings. Since November 2013, I have offered these services through publicly funded initiatives which provide up to $12 \mathrm{~h}$ of consultancy support to each SME engaged with.

From a total of 52 businesses supported in Oxfordshire, UK, nine were initially interviewed for this study on the basis that they occupied non-domestic premises; and did not have dedicated energy managers. Each organisation was provided with $12 \mathrm{~h}$ of funded, formal support. However, in the interests of gathering more indepth data for this study, additional time was spent with each organisation, to develop longer-term relationships.

The study began with the aim of including 10 SMEs in the sample. However, it became clear when reviewing dense findings that a smaller sample would be needed to meet the objective of providing detailed insights into the practice of energy management. Therefore, three SMEs were selected for including in this paper on the basis that they were relatively diverse; representing different sectors, legal structures and building occupancy. The sample includes (1) a business services company (accountancy) which owns and occupies its premises, (2) a charity which occupied part of its site and rented another and (3) a manufacturer/retailer who occupy their site as tenants. Further details of organisational characteristics are provided in Tables 3, 5 and 6. To preserve anonymity, aliases are used for the names of the organisations and interviewees.

\section{Data collection: carbon footprints and interviews}

The majority of the initial $12 \mathrm{~h}$ of funded support was used to conduct carbon footprints for each SME. Meetings with senior members of staff were held to identify the main sources of greenhouse gas (GHG) emissions, agree the footprint scope and establish data collection procedures. A site tour followed the meetings, focusing on the main energy-using practices, and to identify any visible opportunities for savings. Electricity and gas consumption data were gathered from supplier bills, compiled in a spreadsheet and converted into the standard metric for footprint assessments: carbon dioxide equivalent $\left(\mathrm{CO}_{2} \mathrm{e}\right)$. Emissions from vehicles were calculated by combining observed mileage, expenditure on fuels and the efficiency of the vehicle (where possible based on dashboard data; otherwise based on 
manufacturer specification). Results were presented to each SME in a report which quantified the main sources of emissions and recommended options for mitigation.

In addition to the meetings and desk-based support provided, semi-structured interviews, lasting 45$60 \mathrm{~min}$, were carried out with an individual senior member of staff at least 10 months after the initial carbon footprint assessment was completed. Questions focused on the impact and reception of the report and the elements of energy management practice. In this study, the three-element model diagram was presented to interviewees (Fig. 1), who were asked to identify key elements associated with energy management within their organisation, using meanings, materials and competences as categories (Shove et al. 2012). Participants responded positively to this prompt, drawing parallels with other business practices and using the framework to describe how change might be achieved.

The individuals were chosen as they held significant influence in their organisations, including responsibility for energy management. However, dealing primarily with one individual is a limitation of this study, just as it is a hindrance to low carbon advisors when wishing to bring about wider organisational change (Hampton 2018b). Whilst each may have had responsibility for energy management, a practice-perspective highlights how energy is used and managed in mundane ways by all organisational actors, and is shaped by the 'texture of interrelated practices' (Gherardi 2006). Therefore, the ways in which my advice was integrated into organisational norms and meanings depended on how the managers interpreted, responded to and disseminated my findings.

Although they held responsibility for energy within their broad managerial remit, none of the SME managers readily identified as practitioners of energy management. Whether it is necessary for carriers of practice to self-identify as practitioners in order for a practice to be considered as a suitable basis for empirical study is an ongoing debate within practice theory (Bonnington 2015; Hitchings 2012). In energy research, practice theory has been used most notably to investigate overt energy consuming practices such as residential heat comfort (Gram-Hanssen 2010), laundry (Mylan and Southerton 2017) and commuting (Cass and Faulconbridge 2016). Most of these studies use interviews with practitioners who are largely conscious of their activities, and who would agree for instance, that they were actively 'doing the laundry'. By contrast, investigating a peripheral, dispersed practice using interviews with relatively non-reflexive practitioners raises the question of whether their responses can provide reliable, representative evidence.

Hitchings (2012) argues however that all interview data should be interpreted as providing only partial insights into practices, which by their nature have tacit, non-cognitive dimensions. Drawing on this observation, Hampton (2017) highlights the artificial, staged nature of the interview and points out that in many of his interviews with home workers, respondents were talking about their practice for the first time. Rather than consider these as limitations of interviews, these moments reveal insights into the processes of sensemaking and knowledge-construction. Further still, in a study of woodland management, Dandy (2016) considers neglect as a social practice, demonstrating the ability to analyse environmental management practice without the need to engage with highly reflexive and deliberative practitioners. In light of these contributions, the practice of energy management in this paper is interpreted liberally, allowing the analytical lens to focus on a set of activities carried out by actors who are not required to identify as practitioners.

\section{Action research and auto-ethnography}

Providing hands-on advice to SMEs, one objective of this research was to support them to reduce their energy use and environmental impact. The empirical research was conducted alongside this professional practice, and therefore may be considered as a form of action research. Denscombe (2014) summarises four characteristics of this approach: (1) practical implications, (2) dealing with processes of change, (3) involving cyclical feedback and (4) and active participation. Table 2 describes how this research meets these characteristics.

Typical of action-research, this paper draws on autoethnographic data. Meeting notes from engagements with each of the 52 SMEs were written up and shared with the client. In addition, ethnographic field notes were taken. Whilst Denscombe (2014) highlights the necessity for action-researchers to reflect on their practice with the aim of professional self-development, autoethnographic methods require more critical reflexivity (Anderson 2006). It was through this self-refection that it became clear that this research revealed as much about the practice of advice-giving as it did the original focus on the practice of SME energy management. Reflections on this practice are provided in the discussion which follows the three narrative accounts. 
Table 2 Characteristics of action research, based on Denscombe (2014)

\begin{tabular}{|c|c|}
\hline $\begin{array}{l}\text { Action research } \\
\text { characteristic }\end{array}$ & Relevance to this research \\
\hline Practical nature & $\begin{array}{l}\text { My professional practice and associated } \\
\text { research aimed to reduce energy } \\
\text { consumption and carbon emissions from } \\
\text { participating SMEs. }\end{array}$ \\
\hline Processes of change & $\begin{array}{l}\text { My role was to assist and guide SMEs } \\
\text { through a process of reflexive learning } \\
\text { about environmental impact and to } \\
\text { support changing practices. }\end{array}$ \\
\hline Cyclical feedback & $\begin{array}{l}\text { The carbon footprint process involved } \\
\text { collaborating on setting scope, drafting } \\
\text { the report, and together responding to its } \\
\text { recommendations. }\end{array}$ \\
\hline Participation & $\begin{array}{l}\text { I actively participated in helping SMEs } \\
\text { make sense of their own energy } \\
\text { management practices. This paper } \\
\text { provides reflections on my influence as an } \\
\text { external advisor. }\end{array}$ \\
\hline
\end{tabular}

\section{Findings: making sense of energy management}

\section{MRC accountancy}

MRC is an accountancy firm who occupy the same business premises constructed by their founding directors in 1990. The two-storey building uses no gas, and heating is provided by storage heaters, which is 'topped up' using electric fan heaters on the coldest days. Unusually for a service firm, they operate from a small industrial estate, shared with a builder's merchant, three car mechanics and two tool hire firms (Table 3).

I first met Matt in 2009 when he was the Bookkeeper for a consultancy I worked at. Staying loosely in touch thereafter, we met again in 2016 when he had joined MRC in a senior role, tasked with modernising the company, building its brand reputation and diversifying its expertise and client base. The energy and environment goods and services sector is a strategic target for $\mathrm{MRC}$, and the decision to invite me to conduct a carbon footprint was motivated by a desire to better understand their own environmental impact, and in the process, gain knowledge about energy monitoring and environmental technologies. The main findings and recommendations from the carbon footprint process are detailed in Table 4.

For Matt, the carbon footprint exercise was part of his personal campaign to modernise the company. It helped to shed light on the out-dated practices which he was looking to change. These included moving the directors away from using paper diaries, introducing a telecommuting policy and cloud-based IT services. Matt described how energy management was part of this bundle of out-dated practices. The storage heaters offered staff very little control over their thermal environment, and the three different offices were frequently either too cold or too warm, and never in sequence with one another. This generated frustration amongst the staff, which was something they could not afford:

'Because of the competitive nature of our industry. If it's one thing that counts against us, and people might leave, then we need to nip in the bud. It's not something you go for a job interview thinking about, but it's certainly something that makes you think later 'do I want to work here?'. It's deeper than just energy.... It's about how much does our business really care about its people.'

With such strong links to staff retention, Matt explained how the directors each play a role in everyday energy management, with one director responsible for tweaking the settings on the heating system, another for paying suppliers, and all sharing responsibility for listening to staff concerns and discussing investments.

Nine months after the report was submitted, I went back to visit Matt. In the interim, he had been made a

Table 3 MRC organisational characteristics

\begin{tabular}{|c|c|}
\hline Sector & Accountancy \\
\hline Number of staff & 15 \\
\hline Location & $\begin{array}{l}\text { Industrial park on the outskirts } \\
\text { of a small market-town. }\end{array}$ \\
\hline Building type & $\begin{array}{l}\text { Two-storey brick building, } \\
\text { pitched roof, built } 1990 .\end{array}$ \\
\hline Building occupancy & Owner-occupier \\
\hline Energy supply & Electricity (no gas) \\
\hline Primary energy services & $\begin{array}{l}\text { Space heating (electrical storage } \\
\text { heaters); lighting; IT } \\
\text { equipment. }\end{array}$ \\
\hline Typical working practices & $\begin{array}{l}\text { Desk-based office work, with } \\
\text { occasional client visits. }\end{array}$ \\
\hline Business networks & $\begin{array}{l}\text { An acknowledged weakness; } \\
\text { actively joining business } \\
\text { networks. }\end{array}$ \\
\hline $\begin{array}{l}\text { Self-reported awareness of } \\
\text { energy use and } \\
\text { environmental impact }\end{array}$ & Low \\
\hline
\end{tabular}


Table 4 Main findings and recommendations from MRC carbon footprint assessment

\begin{tabular}{|c|c|}
\hline Finding & Recommendation \\
\hline $\begin{array}{l}\text { Heating system } \\
\text { - Is controlled in three ways. (1) } \\
\text { The 'master timer', in the } \\
\text { meter cupboard, which con- } \\
\text { trolled when the storage } \\
\text { heaters were turned on; (2) } \\
\text { Wall-mounted thermostats; } \\
\text { (3) settings on individual } \\
\text { storage heaters. } \\
\text { - The master timer was set } \\
\text { incorrectly. A photograph } \\
\text { taken of the timer taken at } \\
\text { 15:26 shows that the timer } \\
\text { was set to 06:20. This } \\
\text { indicates that the storage } \\
\text { heaters were being } \\
\text { 'charged-up' during the day, } \\
\text { and not benefiting from their } \\
\text { differential tariff. This was } \\
\text { verified using consumption } \\
\text { data which showed } \\
\text { night-time electricity con- } \\
\text { sumption in winter was lower } \\
\text { than in the summer. } \\
\text { Thermostats set to } 25 \mathrm{C} \text {, } \\
\text { including one which } \\
\text { controlled the storage heaters } \\
\text { for an open plan office, but } \\
\text { had been enclosed into a } \\
\text { recently partitioned small } \\
\text { meeting room. } \\
\text { Staff find storage heaters } \\
\text { unresponsive, and frequently } \\
\text { open windows or use fan } \\
\text { heaters to achieve thermal } \\
\text { comfort. }\end{array}$ & $\begin{array}{l}\text { - Conduct tests to review and } \\
\text { better understand the heating } \\
\text { system controls. } \\
\text { - Investigate the potential for } \\
\text { alternative heating systems in } \\
\text { the longer term. }\end{array}$ \\
\hline $\begin{array}{l}\text { - Business travel and } \\
\text { commuting were significant } \\
\text { environmental impacts, } \\
\text { whilst the cost of renting } \\
\text { parking spaces was } \\
\text { significant. }\end{array}$ & $\begin{array}{l}\text { - Develop a home-working } \\
\text { policy, leading to transport } \\
\text { emissions savings, and cost } \\
\text { savings associated with } \\
\text { parking charges. }\end{array}$ \\
\hline $\begin{array}{l}\text { - Opportunities for energy } \\
\text { efficiency include ceiling } \\
\text { insulation, lighting, draught } \\
\text { proofing windows. }\end{array}$ & $\begin{array}{l}\text { - Invest in low cost efficiency } \\
\text { solutions: draught exclusion, } \\
\text { insulated ceiling panels, LED } \\
\text { fittings. }\end{array}$ \\
\hline
\end{tabular}

director of the company, and had implemented some of his modernisation plans. The reception area had been refurbished, presenting visitors with a smarter entrance; the directors were now using online shared diaries; and they were moving to cloud-based software. He told me that the carbon footprint report had been reviewed by the directors, and whilst little had changed in their energy management practice: 'the beauty of the report was to give us a bit more understanding, rather than us just talking about the issues amongst ourselves'.

Whilst in the waiting room before our meeting, I asked the receptionist if could take a look at the metercupboard and found that the master timer was still set incorrectly. When asked if they had had their heating settings reviewed, Matt explained that 'we're still trying to get to the bottom of our heating', which remained frustrating and poorly understood. They asked the company who constructed the building nearly 30 years previous to 'come back to tell us about the [storage heater] units, or at least what they think they can tell us about the units', but this had led to little or no change. Although MRC had sought external advice on their existing heaters, it was clear they had not systematically reviewed the interactions between the three levels of heating controls, as recommended in my report. Instead, Matt explained that they were fed up with the entire system, and were beginning to gather quotations for new heating technologies, having been given some ideas by other business owners in their industrial park.

At the end of our interview, Matt and I used the threeelement model of practice theory to identify the key elements of their energy management practice. The model resonated strongly with Matt, and he used the framework to describe how the material elements of their ageing building and heating system were no longer fit for purpose, how their collective skillsets were underdeveloped, and that a set of negative meanings for staff had resulted. Thinking about how the practice might change for the better, he compared energy management with his recent initiative to introduce cloudbased software:

'We were conscious that the materials we had were not doing the job, so we changed them. To get them embedded into the culture we needed to give a reason, how it fits with the brand. Then we needed to adapt the skills with a thoughtleadership person like myself: why we were going to do it and what skills we needed across the company.'

Similarly, Matt described how for energy management, the introduction of new materials would be the first step, requiring new skills to be developed. A shift of meanings would then follow: from frustration and lack 
of awareness, to achieving comfort and positive attitudes towards energy saving. Whereas my report had recommended prioritising competences regarding existing materials, Matt favoured the PTE model of change, led by new investments in technology. And why had change not yet happened? It was an awkward question. Although Matt considered energy management to be important, his other modernising initiatives were more closely related to the organisation's core activities of servicing clients and winning new business.

\section{Revive}

Revive are a mental health charity operating throughout Oxfordshire. They help those struggling with mental health issues to develop skills and capacity for entering employment (Table 5).

I met with Rita, Revive's Finance and Administration Director at their headquarters, which houses their

Table 5 Revive organisational characteristics

\begin{tabular}{|c|c|}
\hline Sector & Mental health charity \\
\hline Number of staff & 57 \\
\hline Location & $\begin{array}{l}\text { Locations in several market } \\
\text { towns, headquartered in } \\
\text { Oxford. }\end{array}$ \\
\hline Building type & $\begin{array}{l}\text { Café, offices, portakabins and } \\
\text { straw bale outbuilding. }\end{array}$ \\
\hline Building occupancy & $\begin{array}{l}\text { Headquarters: owner-occupier } \\
\text { in one half of main site, and } \\
\text { rent other half from NHS. } \\
\text { Rent elsewhere. }\end{array}$ \\
\hline Energy supply & $\begin{array}{l}\text { Electricity and gas. (Only } \\
\text { electricity at Portakabin site); } \\
\text { small solar array for } \\
\text { self-generation at two sites. }\end{array}$ \\
\hline Primary energy services & $\begin{array}{l}\text { Space heating; cooking and } \\
\text { catering; lighting; IT } \\
\text { equipment; }\end{array}$ \\
\hline Typical working practices & $\begin{array}{l}\text { Desk-based office tasks; } \\
\text { catering; counselling } \\
\text { services; training; } \\
\text { wood-working; horticulture. }\end{array}$ \\
\hline Business networks & $\begin{array}{l}\text { Well integrated into local } \\
\text { community and networked } \\
\text { with other charities. }\end{array}$ \\
\hline $\begin{array}{l}\text { Self-reported awareness of } \\
\text { energy use and } \\
\text { environmental impact }\end{array}$ & High \\
\hline
\end{tabular}

offices, café, shop, garden and workshop. Rita explained that our first project in 2013, when I volunteered to conduct an organisational carbon footprint, was typical of how they work. As a charity, they rely on donations of time, funds, expertise and materials, and making the most of limited resources is at the heart of their culture and everyday practice. Sustainability was a central theme when managing resources, and just as they developed the skills and capabilities of their serviceusers and assisted them in their recovery, they sought to reuse, upcycle and develop all the material resources available to them.

For Revive, one-off gestures or donations can present challenges thereafter. An array of solar panels had been donated to the charity and installed on their café roof. However, when conducting the footprint assessment, I was told they held no data on the renewable electricity generated, consumed, or fed back into the grid. The oneoff project had been led by volunteers and not integrated into Revive's everyday management practices, and knowledge and information about the panels had dispersed. Similarly, Revive welcomed the construction of an innovative, thermally efficient straw bale building by a group of dedicated volunteers in 2007 . However, since then the charity's management team have found that this building material requires regular maintenance, and in the 10 years since its construction, they have had to corral volunteers to carry out significant external repairs and roof works.

Rita mentioned that my carbon footprint report had been well-received internally, and by external stakeholders. Revive's communications team had released a press-release, highlighting the positive aspects of their environmental performance which had been highlighted in the report, including local and organic food sourcing, upcycling activities, and their efficient straw bale building. However, when conducting a second report 4 years later, it became clear that few of the recommendations made in the report had been taken up. Incandescent lightbulbs remained in use, and draughty windows had not been sealed. Rita was blunt in blaming lack of external support and funding. They had recently applied for a $£ 5000$ grant to replace all their light fittings, but had disappointingly only received $£ 165$. Rita was aware that efficient lighting represented a compelling investment which could pay for itself in a matter of months (Gan et al. 2013), but that right now they were in 'dire straits financially and paying our staff is our number one'. 
Rita expressed frustration with the energy efficiency of some of their offices. One half of Revive's headquarters are located in a purpose built, modern and efficient premises, whilst the other is an older building rented from the National Health Service (NHS) where 'the windows don't fit properly and the roof vents flap up and down in the wind'. In the NHS building, energy bills are included in their rent, so they have no data or visibility of their consumption. This was seen by Rita as a positive situation:

'We're quite lucky that all of our electricity here comes in with our rent. So there is no expenditure for our headquarters and it doesn't tend to go up with our consumption, which is nice, because that's a fixed cost.'

Visibility emerged as a theme for Rita when discussing Revive's environmental impact and ethos of sustainability. When populating the elements of energy management practice using the three-element diagram, Rita identified heating controls and building fabric as prominent materials, but preferred to talk about more visible, tangible resources such as waste. On this, she spoke animatedly about their practices of re-use, 'upcycling' and minimising waste going to landfill. In a small organisation, the distinction between the business and personal domains was frequently blurred and their café manager, who runs a smallholding, had started to take home their shredded office paper to use as animal bedding. Becoming impassioned, Rita shared another story of when she was on holiday and her less creative colleagues paid to have confidential paper shredded and collected. 'That really sits in my throat', she said.

Whereas the competences involved in energy management were associated with the uninspiring activities of data management, funding applications and turning things off after others, sustainable resource management involved creativity and originality. Like Matt from MRC, the three-element model prompted Rita to draw parallels between energy management and another practice. The new General Data Protection Regulation (GDPR) would mean more energy-intensive paper shredding and would require Revive to dispose of their library of archive tapes. As an example of how this new practice was being incorporated into Revive's culture of resource efficiency, she told me how a member of staff was 'going to take them and knit them into mats' which could then be sold in their shop.
Whereas most of my questions and underlying assumptions about energy management practice were focused on activities internal to the charity, Rita helped me to realise that this was a simplistic understanding of the nature of the organisation. Using examples of where they had shared excess resources with their network of local charities, and highlighting their reliance on external volunteers, she identified 'community' as a key meaning when completing the three-element diagram together.

\section{Giftive}

Giftive manufacture 'make-your-own' kits for food enthusiasts, helping customers create products such as ricotta cheese, cured bacon and infused gin. Sean started the company in 2013 in his kitchen, during university vacations. He explained to me that despite the niche nature of his business, it operates in a crowded marketplace, with competitors frequently rebranding and undercutting his innovations. This meant they had to continually develop the Giftive product range in line with fashions and trends. Having doubled revenue every year, the youthful company are now expanding into non-foods, and have opened a manufacturing site in China, where his business partner grew-up. Here they are creating kits to follow the latest trends, which include wall-mounted rainbow-unicorns, and gin themed cross-stitch kits (Table 6).

Whereas for their first 3 years, the founding partners had manufactured the kits themselves, working long days in the run-up to Christmas, 2016 saw them become employers for the first time. This marked a significant shift in Sean's daily practice, requiring him to develop a new set of skills: meeting the needs of staff, overseeing the company's financial health, whilst continuing to innovate in order to grow.

They now have four employees, and Sean told me that managing energy as a business has been strongly influenced by the need to react to the rapid change they have experienced. Our discussion focused on heating as their primary source of energy consumption. During their first winter occupying a light industrial unit, they largely managed without heating, using movement and adrenaline to keep them going. Taking on their first employee made them conscious of the need to provide comfort, and question the suitability of their heating practices, and they bought two electric heaters in winter 2016 which could be 'pointed at' the person who felt the 
Table 6 Giftive organisational characteristics

\begin{tabular}{|c|c|}
\hline Sector & $\begin{array}{l}\text { Manufacturing and online } \\
\text { retailer }\end{array}$ \\
\hline Number of staff & 6 \\
\hline Location & $\begin{array}{l}\text { Industrial park on the outskirts } \\
\text { of a small market-town. }\end{array}$ \\
\hline Building type & $\begin{array}{l}\text { Two-storey light industrial, } \\
\text { pitched roof, built c1980s. }\end{array}$ \\
\hline Building occupancy & 3-year lease agreement. \\
\hline Energy supply & Electricity (no gas) \\
\hline Primary energy services & $\begin{array}{l}\text { Space heating, small-scale } \\
\text { packing machinery, lighting. }\end{array}$ \\
\hline Typical working practices & $\begin{array}{l}\text { Assembly line manufacturing; } \\
\text { desk-based office tasks. }\end{array}$ \\
\hline Business networks & $\begin{array}{l}\text { Primarily online, through } \\
\text { platforms such as Etsy, } \\
\text { Amazon, E-Bay. }\end{array}$ \\
\hline $\begin{array}{l}\text { Self-reported awareness of } \\
\text { energy use and } \\
\text { environmental impact }\end{array}$ & Mixed feelings \\
\hline
\end{tabular}

most need for warmth. However, taking on three additional staff in 2017 tested their ad hoc solution, which led to a discussion between the directors about the culture of the organisation and its environmental values. Having investigated the option of providing a propanebased heating system, they instead opted to provide thermal undergarments for all staff.

Sean described how this decision was related to the way the company's culture and identity was unfolding in the course of expansion. Were they like their car mechanic neighbours, whose staff accepted working in outdoor conditions and got their hands dirty, or were they trying to emulate a high-tech start-up, with a youthful culture, complete with office furniture made from pallets? The meanings associated with working at Giftive were changing, and this had implications for the various elements of everyday practice. Sean described how these open questions about the organisation were playing out in the ways they thought about, and managed energy:

'It's like we're a group of students who all live together. We're all quite young. We're willing to put up with [colder temperatures], whereas if we had an older person, or somebody who is, like, a bit less cool, then we'd have to heat [the space] a bit more... It's like a home, but where the practices are less established. Because we're new. Because we've never ever been in a job or a business before. So we just do things completely our own way, and make it up.'

Being Sinophiles, the two owner-managers also wished to embed some Asian traditions into their organisational culture. Sean conjectured that the decision to buy thermals was related to these efforts:

'My business partner wears thermals and is always super warm. It's also probably a Chinese cultural thing too. He comes from a country where it does get super cold in the winter and thermals are commonplace. So we decided to buy them from a Japanese company, because in Japan in winter it gets super cold, the same as in China. So maybe it's us taking that culture across.'

Sean explained how energy management became more prominent as a practice during the winter months, but was managed differently during the Christmas rush. He was aware that the electric heaters were expensive to run, but had competing priorities:

'When we first got our heaters we would turn them on for two hours at a time, and we would remember to turn them off. We gave up on that, because Christmas is our busy time, so at that time of the year basically anything that makes our life simpler or easier, we just do. So we just turn them on all the time and just leave it.'

Just as Giftive were asking themselves questions about their organisational culture and meaning as they underwent rapid growth, they also had ambivalent feelings about their environmental impact. On the one hand, Sean felt strongly about the need to tackle climate change and reducing the environmental impact from their business, and on the other, felt powerless when thinking about the business as an entity. When asked what his thought the business's biggest environmental impacts were, Sean said:

'I think it's the whole concept of the business. Ultimately, we sell packaging. We sell stuff packaged in boxes which doesn't need to be packaged in boxes. People could probably do this for themselves. It's all kind of superfluous, and slightly wasteful anyway, so I think we just... give up on which bits are worse than others.' 
Sean described how responding to my questions about energy and environmental impact was the first time he had thought in-depth about these issues, and it made him uncomfortable. Earlier in the interview, we had discussed whether he felt that the carbon footprint associated with air freighting their products was their responsibility, he had insisted that their scope included their own on-site operations, and that transport was the remit of the haulier. However, later in the discussion he said:

'...but I do feel a bit guilty. You make me feel guilty about it!'

Undergoing rapid growth, international expansion and operating in a niche market where continual innovation is the key to success, there are open questions for Giftive relating to its culture, purpose and practices. Energy and environmental management practices are bound up in this bundle of sensemaking processes.

\section{Discussion: energy management practice, business advice and knowledge production}

The three narrative case studies presented above indicate that energy management is woven into the culture and practices of small organisations, and is influenced by the ongoing sensemaking processes which give organisations their character. Energy underpins the doings and sayings of all organisations, and although each SME in this study described its management as a peripheral and non-strategic activity, it becomes clear when seen through a practice lens that it can incorporate meanings, materials and competences which relate to an organisation's core identity.

This discussion is structured into two parts. The first part uses examples from each SME to draw linkages between material elements of practice and processes of organisational knowledge construction. These demonstrate the value of practice theory and sensemaking in helping to provide insights into energy management practice. The second part reflects on the relationship between business advisors and SMEs, including the power dynamics involved in providing expert advice.

\section{Energy management practice}

Underpinned by a 'flat' ontology, practice theory affords prominence to material artefacts, and Nicolini argues that when seeking to understand organisational practices it is often 'the perceived object that bestows actions with continuity, coherence, and meaning' (Nicolini 2012, p. 225). By focusing on the three elements of practice, each of the accounts above show how material objects were at the centre of the unfolding story of energy management.

For MRC, meanings of frustration and a deficit of competences were imbued in thermostats, timers and ageing storage heaters. Navigating towards an energy management solution became tied up in an existential narrative of change, modernisation and staff retention. Matt was actively seeking to alter the meanings embedded in the 'texture' of organisational practices (Gherardi 2006). Despite the recommendation made to MRC to review the ways that its existing heating system was being used and understood, Matt's preference was for a larger, more comprehensive solution. For him, a major investment in a new technology, as discussed with other local business leaders, would deliver a performative statement about MRC's status as an innovative, modern company. Prompted by the three-element diagram, Matt explained that he thought that an investment in radical, material changes would lead to changes in associated meanings and competences.

Materiality also influences the ongoing construction of organisational identity at Revive, where optimal resource utilisation is at the heart of the charity's ethos, and finding creative means to prevent waste was a practice that staff felt passionate about. The corollary of having materiality at the heart of organisational identity however, was that at Revive, energy was comparatively more peripheral. With energy consumption and costs hidden within their rent, it was immaterial for Rita. This seemed to prevent her from prioritising its conservation when compared with more visible resources such as café and office waste. The stories from Revive help to corroborate the practice-theoretical view that organisations ought not to be considered as fixed entities, but as products of ongoing organising processes (Feldman and Orlikowski 2011; Nicolini 2012). Making use of donated resources such as solar panels and volunteer time requires agility, and it is through these organising practices that Revive is developing its own culture and memory (Schatzki 2006).

Giftive is a youthful company, trying to make sense of its rapid growth and establish a corporate identity. Like Revive, this identity was imbued in the materials they handled. Manufacturing 'do it yourself' kits, 
bricolage was at the heart of their organisational practice, and this carried through to energy management (Royston 2014). Taking the decision to buy their staff thermal garments rather than invest in a propane heating system was a performative gesture, affirming their creative, innovative identity. It is also evidence of energyrelated decision making which the conventional PTE model fails to capture. In this case, the problem of meeting staff comfort needs was tackled not by making an energy service more efficient or investing in machinery, but by offering a sufficient solution (Thomas et al. 2017). This finding indicates that low-tech means of achieving comfort may be as commonplace for SMEs as they have been shown to be for home workers (Hampton 2017). Rather than asking 'which are the most cost-effective options for energy efficiency', an attention to practices highlights how the meanings associated with energy were dynamically linked to materials and know-how. At Giftive, clothing, bodies and adaptive comfort were at the centre of energy management practice, elements of practice through which a youthful, kinetic culture was being performed.

For each of these SMEs, narratives revealed how energy management practice is bound up in the continually unfolding processes of organisational meaningmaking. The three-element model of practice theory helped to show how organisational identity formation was being played out in material objects and through forms of embodied competences.

The practice of advising SMEs

As external providers of expertise, business advisors have a role in constructing new meanings and knowledge for the organisations with which they become involved. When this professional practice is used for research purposes, the action-researcher also has a responsibility to reflect on their influence (Denscombe 2014).

Gathering energy data, conducting carbon footprint assessments and asking business managers to reflect on their practices in interviews, I was instrumental in bringing certain elements of practice to the fore and influencing organisational sensemaking. Elements foregrounded in this process included material objects such as thermostats, clothing and storage heaters, and my probing questions drew out meanings of comfort and organisational identity. By enquiring about a seemingly peripheral practice, discussions about organisational competences such as data management, heating controls, adaptive comfort and staff morale emerged, often alongside the identification of skills deficits. As the relationships continued beyond initial carbon footprint assessments, it became clear that our discussions were leading participants to make connections between energy management and other practices such as human resource management and business development activity. Through these processes, I was deliberately helping to bring the dispersed and disregarded practice of energy management to the fore for each SME.

The carbon footprint assessments and face-to-face advice provided information to the SMEs about how they consumed, conserved and even avoided energy through working practices. Although as a business advisor, I had the clear and benevolent intention to help the SMEs manage energy more efficiently, the translation of this was not always predictable. MRC opting to focus on a large-scale investment rather than fully making sense of their failing heating system is an example of how my intervention had been absorbed into Matt's logic of change. Whilst for Giftive, my relationship led Sean to reflect on the relationship between the core activities of his business and its environmental sustainability. Concluding that their products were 'all kind of superfluous, and slightly wasteful anyway', he appeared at the end of our final interview to feel demoralised and demotivated. As a young and environmentally conscious business owner, he struggled with the realisation that energy management would do little to ameliorate the environmental impact arising from his business.

These findings have a number of implications. Firstly, they show that as business advisors become entwined in organisational sensemaking and always-changing practices, outcomes can be unpredictable (Georg and Fussel 2000; Moss et al. 2008). On the one hand, it may be reasonable to assume that in-depth engagements with SMEs relating to their everyday business practices would lead to greater awareness of their environmental impact and greater motivation to take mitigating action. However, on the other, the relationship between awareness and pro-environmental action is far from clear (Parker et al. 2009; Revell et al. 2010). As Sean's experience illustrates, making sense of organisational environmental impact with the help of an advisor can highlight the limited control that its directors possess to effect meaningful change.

Secondly, the MRC directors' preference for largescale investment corroborates evidence that options for energy conservation involving zero-capital investment 
are not necessarily the most appealing to business owners (DECC 2014). This example demonstrates that more important than the content of information, advice or reports provided by external advisors, are the processes by which such resources are absorbed and made sense of by organisations. These processes are unique to each organisation, bound up in its traditions, cultures and established practices (Weick 1995; Weick et al. 2005; Brown et al. 2015). Whilst this finding might be unsurprising to many social scientists, as an actionresearcher and business advisor, it is also frustrating. If each organisation manages energy in unique ways, and absorbs advice unpredictably, does this mean that there can be no scalable solutions to accelerate the energy transition amongst the 5.7-m SMEs in the UK? As has been argued elsewhere, such findings indicate that for low carbon business advisors, it is the 'soft stuff that's hard' (Hampton 2018b). However, rather than resort to PTE approaches, this indicates the need for new forms of energy advice, paying attention to the stories and practices unique to the organisations being supported.

The findings presented in this paper also tell us about the power-relations at play in the industry of energy advice-giving (Lutzenhiser 2014). As Nicolini (2012) suggests, practice theory can reveal the dynamics of power within and outside of organisations by 'zooming in' on the elements of practice. As discussed above, the majority of energy and environmental advice provided to SMEs takes the form of technical assessments of building efficiency and investment payback calculations, and are influenced by the epistemological traditions of the PTEM (Fleitera et al. 2012; Thollander et al. 2015; DECC 2015; BEIS 2017b). These approaches tend to include assumptions about linear, rational decision-making processes, and in turn help to consolidate and extend forms of economic and technical knowledge production amongst SMEs (Banks et al. 2012; Lutzenhiser 2014; McCormack and Schwanen 2011; Revell 2007). When considered using the threeelement model of practice theory, such approaches place emphasis on particular material technologies such as heating systems and electrical appliances, and generate a need for highly technical competences often external to the organisation. It may be argued that these serve to sustain the collective interests of certain practitioners, such as suppliers of technology, energy consultants and business advisors themselves. By contrast, the findings in this paper suggest that for SMEs to reduce their energy consumption and environmental footprint, management practice needs to be more prominently integrated with the core organising processes which continually define and reproduce the organisation itself. This presents a challenge to the community of SME energy advisors to provide support and advice which is meaningful, comprehensible and relevant.

\section{Conclusions}

This study initially set out to uncover insights into energy management practice amongst SMEs using practice theory. However, it became clear that the rich, longitudinal findings revealed as much about this as it did about the practice of providing energy and environmental advice to SMEs. This learning process was not accidental, and the expanded focus of this paper resulted from the process of applying its theoretical framework. Just as practice theory and sensemaking focus on organisations as they happen, they encourage reflexivity and flexibility from researchers and advisors too (Schmidt 2016). This paper now concludes by discussing implications for policy-makers, SME advisors and researchers.

When developing policy to address the challenge of decarbonising SMEs, the provision of expert advice is a preferred approach by policy-makers (IEA 2015). Energy advisors across the EU are funded to spend up to $12 \mathrm{~h}$ with SMEs, aiming to engender more proactive approaches to managing energy and environmental impact (MHCLG 2018). However, the outcomes of relationships developed between SMEs and advisors cannot be easily predicted. Drawing on auto-ethnographic data and longitudinal advisor-SME interactions, this paper has demonstrated the important but uncertain role that external advice plays in producing knowledge and steering SME practices. Using narrative accounts of energy management practice in three SMEs, it has shown how energy management involves a diverse set of materials, and associated meanings, skills and knowledge which are interwoven with organisational sensemaking processes. Reconceptualising energy management as a dynamic practice helps to explain the chaotic and unpredictable ways in which expert advice is absorbed into organisations. Like tributaries of a flowing river, information about energy consumption and carbon footprints become part of the ongoing, turbulent sensemaking processes from which an organisation's identity and ontological character surface 
(Nicolini 2012). For policy-makers seeking to understand how SMEs respond to the provision of energy and environmental advice, these findings may help to explain why take-up of energy efficiency opportunities and behavioural change remains sporadic.

Perhaps influenced by the dominant 'problem framing' of organisational energy management, the practice was initially considered by the SME managers in this study to be a technical activity. It was something that larger businesses may undertake, and none identified themselves as practitioners of energy management. This framing is consolidated by external energy advisors, who typically conduct a technical energy audit, followed by a business case for one-off investments in efficiency upgrades. As Lutzenhiser (2014) has shown, this conventional approach is influenced by the physical, technical and economic paradigm, which is epistemologically narrow and downplays the role of low-tech materials and tacit knowledge. To make energy advice more salient for SMEs (Mallaburn 2016), advisors must attend to the 'soft stuff' (Hampton 2018b), including how organisational narratives are constructed. This need not be overwhelming however, and the findings in this paper show the importance of attending to practice materialities. For low carbon advisors, this requires an expanded perspective on what materials matter. It is not just heating and lighting systems, nor building fabric that require attention, but clothing, bodies, donated resources and waste.

Powells et al. (2015) called for the further application of practice theory to SMEs in the field of energy research. This paper has responded to this call by using the three-element model of practice theory to show how the practice of energy management was characterised by a range of dispersed activities such as tweaking controls, achieving personal comfort or preventing waste. This approach has shown how energy management was bound up in organisational cultures and meanings, these in turn being influenced by material elements and embodied competences.

Practice theory has also been used in this paper more unconventionally, generating insights for future research. Firstly, whereas practice theory has been used to examine energy consuming practices in which interviewees readily identify as practitioners, this paper has focused on three organisations which had not identified energy management as a strategically relevant practice at the start of the advisory relationship. Rather than limiting the value of findings, this led data collection to be an open, collaborative process, whereby respondents were learning, reflecting, and discovering how energy management integrates with the nexus of doings and sayings which constitute their organisation. Secondly, in support of this collaborative process, the threeelement model was used in interviews as an aid for SME managers to reflect in new ways on their own practices. By encouraging participants to discover the ways in which they are already managing energy, the diagram appeared to enliven respondents, who responded by reflecting on processes of change within their organisations, and by making links with other nascent practices. This method is not only useful for energy researchers, but could also present an alternative approach for energy advisors to engage SMEs in discussions about the 'soft stuff'. This collaborative, pedagogical approach may help to empower SMEs to be more proactive about their energy use and environmental impact. Whilst this paper has presented narratives from three SMEs, further research using ethnographic methods may seek to investigate which practices influence how external advice is received, absorbed and responded to.

Acknowledgements Thanks go to all the participants in this research, as well as Tina Fawcett and Sarah Darby for their thoughtful comments and constructive feedback.

Funding This research was funded by the UK Energy Research Centre and the Economic and Social Research Council.

\section{Compliance with ethical standards}

Conflict of interest The author declares that he has no conflict of interest.

Open Access This article is distributed under the terms of the Creative Commons Attribution 4.0 International License (http:// creativecommons.org/licenses/by/4.0/), which permits unrestricted use, distribution, and reproduction in any medium, provided you give appropriate credit to the original author(s) and the source, provide a link to the Creative Commons license, and indicate if changes were made.

\section{References}

Abolafia, M. Y. (2010). Narrative construction as sensemaking: How a Central Bank thinks. Organization Studies, 31(3), 349-367. https://doi.org/10.1177/0170840609357380. 
Anderson, L. (2006). Analytic autoethnography. Journal of Contemporary Ethnography, 35(4), 373-395. https://doi. org/10.1177/0891241605280449.

Andrews, R. N. L., \& Johnson, E. (2016). Energy use, behavioral change, and business organizations: Reviewing recent findings and proposing a future research agenda. Energy Research \& Social Science, 11, 195-208. https://doi. org/10.1016/j.erss.2015.09.001.

Banks, N., Fawcett, T., \& Redgrove, Z. (2012). What are the factors influencing energy behaviours and decision-making in the non-domestic sector? A rapid evidence assessment.

BEIS. (2017a). ERDF Case Study Booklet. https://www.gov. uk/government/uploads/system/uploads/attachment_ data/file/656518/2014-2020_ERDF_Case_Study_ Booklet_2017.pdf. Accessed 16 Nov 2017.

BEIS. (2017b). Business awareness and uptake of energy audits.

Bonnington, O. (2015). The indispensability of reflexivity to practice: the case of home energy efficiency. Journal of Critical Realism, 14(5), 461-484. https://doi.org/10.1179 /1572513815Y.0000000009.

Bourdieu, P. (1977). Outline of a theory of practice. Cambridge: Cambridge University Press.

Brown, A. D., Colville, I., \& Pye, A. (2015). Making sense of sensemaking in organization studies. Organization Studies, $36(2), 265-277$. https://doi.org/10.1177 /0170840614559259.

Cass, N., \& Faulconbridge, J. (2016). Commuting practices: new insights into modal shift from theories of social practice. Transport Policy, 45, 1-14. https://doi.org/10.1016/j. tranpol.2015.08.002.

Clegg, S., \& Hardy, C. (1996). Organizations, organization and organizing. In S. Clegg, C. Hardy, \& W. Nord (Eds.), Handbook of organization studies (pp. 1-28). London: Sage.

Coles, T., Dinan, C., \& Warren, N. (2016). Energy practices among small- and medium-sized tourism enterprises: a case of misdirected effort? Journal of Cleaner Production, 111, 399-408. https://doi.org/10.1016/j.jclepro.2014.09.028.

Cooremans, C. (2012). Investment in energy efficiency: the characteristics of investments matter? Energy Efficiency, 5(4), 497-518. https://doi.org/10.1007/s12053-012-9154-x.

Corradi, G., Gherardi, S., \& Verzelloni, L. (2010). Through the practice lens: where is the bandwagon of practice-based studies heading?, Through the practice lens: where is the bandwagon of practice-based studies heading? Management Learning, 41(3), 265-283. https://doi.org/10.1177 $/ 1350507609356938$.

Cunliffe, A., \& Coupland, C. (2012). From hero to villain to hero: Making experience sensible through embodied narrative sensemaking. Human Relations, 65(1), 63-88. https://doi. org/10.1177/0018726711424321.

Currie, G., \& Brown, A. D. (2003). A narratological approach to understanding processes of organizing in a UK hospital. Human Relations, 56(5), 563-586.

Dandy, N. (2016). Woodland neglect as social practice. Environment and Planning A, 48(9), 1750-1766. https://doi.org/10.1177/0308518X16651266.

DECC. (2014). Research to assess the barriers and drivers to energy efficiency in small and medium sized enterprises. DECC.

DECC. (2015). 2010 to 2015 government policy: Energy demand reduction in industry, business and the public sector.
DECC. (2016). Potential of smart technologies in SMEs.

Denscombe, M. (2014). The Good Research Guide: For Smallscale Social Research Projects. McGraw-Hill Education (UK).

Feldman, M. S., \& Orlikowski, W. J. (2011). Theorizing practice and practicing theory. Organization Science, 22(5), 12401253. https://doi.org/10.1287/orsc.1100.0612.

Fleitera, T., Schleich, J., \& Ployplearn, R. (2012). Adoption of energy-efficiency measures in SMEs - an empirical analysis based on energy audit data. Energy Policy, 51, 863-875.

Gan, C. K., Sapar, A. F., Mun, Y. C., \& Chong, K. E. (2013). Techno-economic analysis of LED lighting: a case study in UTeM's faculty building. Procedia Engineering, 53, 208216. https://doi.org/10.1016/j.proeng.2013.02.028.

Georg, S., \& Fussel, L. (2000). Making sense of greening and organizational change. Business Strategy and the Environment, 9(3), 175-185.

Gherardi, S. (2006). Organizational knowledge: the texture of workplace learning. Wiley.

Gherardi, S. (2009). Knowing and learning in practice-based studies: an introduction. The Learning Organization, 16(5), 352359. https://doi.org/10.1108/09696470910974144.

Gram-Hanssen, K. (2010). Residential heat comfort practices: Understanding users. Building Research and Information, $38(2), 175-186$. https://doi.org/10.1080 /09613210903541527.

Hampton, S. (2017). An ethnography of energy demand and working from home: exploring the affective dimensions of social practice in the United Kingdom. Energy Research \& Social Science, 28, 1-10. https://doi.org/10.1016/j. erss.2017.03.012.

Hampton, S. (2018a). Policy implementation as practice? Using social practice theory to examine multi-level governance efforts to decarbonise transport in the United Kingdom. Energy Research \& Social Science, 38, 41-52. https://doi. org/10.1016/j.erss.2018.01.020.

Hampton, S. (2018b). "It"s the soft stuff that's hard': Investigating the role played by low carbon small- and medium-sized enterprise advisors in sustainability transitions. Local Economy, 33(4), 384-404. https://doi.org/10.1177 10269094218778526.

Hampton, S., \& Fawcett, T. (2017). Challenges of designing and delivering effective SME energy policy. In ECEEE Summer Study Proceedings (Vol. 1-353-17). Presented at the ECEEE, France.

Hargreaves, T. (2011). Practice-ing behaviour change: Applying social practice theory to pro-environmental behaviour change. Journal of Consumer Culture, 11(1), 79-99. https://doi.org/10.1177/1469540510390500.

Harquail, C. V., \& King, A. W. (2010). Construing organizational identity: the role of embodied cognition. Organization Studies, 31(12), 1619-1648. https://doi.org/10.1177 /0170840610376143.

Higginson, S., McKenna, E., Hargreaves, T., Chilvers, J., \& Thomson, M. (2015). Diagramming social practice theory: an interdisciplinary experiment exploring practices as networks. Indoor and Built Environment, 24(7), 950-969. https://doi.org/10.1177/1420326X15603439.

Hitchings, R. (2012). People can talk about their practices. Area, 44(1), 61-67. https://doi.org/10.1111/j.14754762.2011.01060.x. 
IEA. (2015). Accelerating Energy Efficiency in Small and Medium-sized Enterprises.

Janda, K., Wilson, C., Moezzi, M., \& Bartiaux, F. (2015). Improving efficiency in buildings: conventional and alternative approaches. In P. Ekins, M. Bradshaw, \& J. Watson (Eds.), Global energy: issues, potentials and policy implications (pp. 163-188). Oxford: Oxford University Press.

Johnson, G., Langley, A., Melin, L., \& Whittington, R. (2007). Strategy as practice: research directions and resources. Cambridge: Cambridge University Press.

Kuijer, L. (2014). A call for more practice theory on the future. In Demanding ideas: where theories of practice might go next (Vol. Working Paper 12). Windermere.

Lave, J., \& Wenger, E. (1991). Situated learning: legitimate peripheral participation. Cambridge: Cambridge University Press.

Lizardo, O. (2004). The cognitive origins of Bourdieu's habitus. Journal for the Theory of Social Behaviour, 34(4), 375-401.

Lutzenhiser, L. (2014). Through the energy efficiency looking glass. Energy Research \& Social Science, 1, 141-151. https://doi.org/10.1016/j.erss.2014.03.011.

Mallaburn, P. (2016). A new approach to non-domestic energy efficiency policy. https://www.theccc.org.uk/wpcontent/uploads/2016/10/A-new-approach-to-non-domesticenergy-efficiency.pdf. Accessed 14 July 2017.

McCormack, D. P., \& Schwanen, T. (2011). Guest editorial: the space-Times of decision making. Environment and Planning A, 43(12), 2801-2818. https://doi.org/10.1068 /a44351.

MHCLG. (2018). Output indicator definitions guidance for the European regional development fund for England.

Moss, J., Lambert, C. G., \& Rennie, A. E. W. (2008). SME application of LCA-based carbon footprints. International Journal of Sustainable Engineering, 1(2), 132-141. https://doi.org/10.1080/19397030802332930.

Mylan, J., \& Southerton, D. (2017). The social ordering of an everyday practice: the case of laundry. Sociology, 003803851772293 . https://doi.org/10.1177 /0038038517722932.

Nicolini, D. (2012). Practice theory, work, and organization: an introduction. Oxford: Oxford University Press.

Orlikowski, W. J. (2002). Knowing in practice: enacting a collective capability in distributed organizing. Organization Science, 13(3), 249-273. https://doi.org/10.1287 /orsc.13.3.249.2776.

Parker, C. M., Redmond, J., \& Simpson, M. (2009). A review of interventions to encourage SMEs to make environmental improvements. Environment and Planning. C, Government \& Policy, 27(2), 279-301. https://doi.org/10.1068/c0859b.

Powells, G., Bell, S., Judson, E., Lyon, S., Wardle, R., Capova, K., \& Bulkeley, H. (2015). Fostering active network management through SMEs' practises. Energy Efficiency, 9, 1-14. https://doi.org/10.1007/s12053-015-9382-y.

Revell, A. (2007). The ecological modernisation of SMEs in the UK's construction industry. Geoforum, 38(1), 114-126. https://doi.org/10.1016/j.geoforum.2006.07.006.

Revell, A., \& Blackburn, R. (2007). The business case for sustainability? An examination of small firms in the UK's construction and restaurant sectors. Business Strategy and the Environment, 16(6), 404-420. https://doi.org/10.1002 /bse.499.
Revell, A., Stokes, D., \& Chen, H. (2010). Small businesses and the environment: turning over a new leaf? Business Strategy and the Environment, 19, 273-288. https://doi.org/10.1002 /bse.628.

Royston, S. (2014). Dragon-breath and snow-melt: know-how, experience and heat flows in the home. Energy Research \& Social Science, 2, 148-158. https://doi.org/10.1016/j. erss.2014.04.016.

Sa, A., Paramonova, S., Thollander, P., \& Cagno, E. (2015). Classification of industrial energy management practices. Energy Procedia, 75, 2581-2588. https://doi.org/10.1016/j. egypro.2015.07.311.

Schatzki. (2005). Peripheral vision: the sites of organizations. Organization Studies, 26(3), 465-484. https://doi. org/10.1177/0170840605050876.

Schatzki, T. R. (2006). On organizations as they happen. Organization Studies, 27(12), 1863-1873. https://doi. org/10.1177/0170840606071942.

Schmidt, R. (2016). The methodological challenges of practising praxeology. In G. Spaargaren, D. Weenink, \& M. Lamers (Eds.), Practice Theory and Research: Exploring the dynamics of social life (pp. 43-59). Abingdon: Routledge.

Shove, E. (2003). Converging conventions of comfort, cleanliness and convenience. Journal of Consumer Policy, 26(4), 395418. https://doi.org/10.1023/A:1026362829781.

Shove, E., \& Pantzar, M. (2005). Consumers, producers and practices: understanding the invention and reinvention of Nordic walking. Journal of Consumer Culture, 5(1), 43-64. https://doi.org/10.1177/1469540505049846.

Shove, E., \& Walker, G. (2014). What is energy for? Social practice and energy demand. Theory, Culture and Society, 31(5), 41-58. https://doi.org/10.1177/0263276414536746.

Shove, E., Pantzar, M., \& Watson, M. (2012). The dynamics of social practice. Thousand Oaks: SAGE Publications.

Spaargaren, G., Weenink, D., \& Lamers, M. (2016). Practice theory and research: exploring the dynamics of social life. Abingdon: Routledge.

Spotswood, F., Chatterton, T., Tapp, A., \& Williams, D. (2015). Analysing cycling as a social practice: an empirical grounding for behaviour change. Transportation Research Part F: Traffic Psychology and Behaviour, 29, 22-33. https://doi. org/10.1016/j.trf.2014.12.001.

Thollander, P., Kimura, O., Wakabayashi, M., \& Rohdin, P. (2015). A review of industrial energy and climate policies in Japan and Sweden with emphasis towards SMEs. Renewable and Sustainable Energy Reviews, 50, 504-512. https://doi.org/10.1016/j.rser.2015.04.102.

Thomas, S., Brischke, L.-A., Thema, J., Leuser, L., \& Kopatz, M. (2017). Energy sufficiency policy: how to limit energy consumption and per capita dwelling size in a decent way. Wuppertal Institut für Klima, Umwelt, Energie.

Trianni, A., \& Cagno, E. (2011). Energy Efficiency Barriers in Industrial Operations: Evidence from the Italian SMEs Manufacturing Industry. Energy Productivity in Industry: Partners and Opportunities, 12.

Trianni, A., \& Cagno, E. (2012). Dealing with barriers to energy efficiency and SMEs: some empirical evidences. 7th Biennial International Workshop "Advances in Energy Studies," 37(1), 494-504. https://doi.org/10.1016/j. energy.2011.11.005. 
Warren, P. (2017). The potential of smart technologies and microgeneration in UK SMEs. Energies, 10(7), 1050. https://doi. org/10.3390/en10071050.

Weick, K. E. (1979). The social psychology of organizing. Random House.

Weick, K. E. (1995). Sensemaking in organizations. Thousand Oaks.

Weick, K. E., Sutcliffe, K. M., \& Obstfeld, D. (2005). Organizing and the process of sensemaking. Organization Science, 16(4), 409-421. https://doi.org/10.1287/orsc.1050.0133.

Whittington, R. (2006). Completing the practice turn in strategy research, completing the practice turn in strategy research.
Organization Studies, 27(5), 613-634. https://doi. org/10.1177/0170840606064101.

Wilhite, H. (2008). New thinking on the agentive relationship between end-use technologies and energy-using practices. Energy Efficiency, 1(2), 121-130. https://doi.org/10.1007 /s12053-008-9006-x.

Williamson, D., Lynch-Wood, G., \& Ramsay, J. (2006). Drivers of environmental behaviour in manufacturing SMEs and the implications for CSR. Journal of Business Ethics, 67(3), 317-330. https://doi.org/10.1007/s10551-006-9187-1. 